\title{
Goblet Cell Carcinoid Tumors of the Appendix: A Report of Two Cases, Review of a Rare Clinical Entity, and Guidelines for Treatment
}

\author{
Carlos Álvarez-Laso', Enedina Azcano', Juan F. Carrion'1, Diana Rodríguez² ${ }^{2}$ José R. Riera² \\ ${ }^{1}$ Surgery Department, Hospital de Cabueñes, Gijón, Spain \\ ${ }^{2}$ Pathology Department, Hospital de Cabueñes, Gijón, Spain \\ Email: alvarezlaso@hotmail.com
}

How to cite this paper: Álvarez-Laso, C., Azcano, E., Carrion, J.F., Rodríguez, D. and Riera, J.R. (2017) Goblet Cell Carcinoid Tumors of the Appendix: A Report of Two Cases, Review of a Rare Clinical Entity, and Guidelines for Treatment. Open Access Library Journal, 4: e3256.

http://dx.doi.org/10.4236/oalib.1103256

Received: December 3, 2016

Accepted: January 2, 2017

Published: January 5, 2017

Copyright $\odot 2017$ by authors and Open Access Library Inc.

This work is licensed under the Creative Commons Attribution International License (CC BY 4.0).

http://creativecommons.org/licenses/by/4.0/ (c) (i) Open Access

\begin{abstract}
Goblet cell carcinoid tumor is a rare clinical entity which is usually diagnosed either as acute appendicitis or advanced cancer. Its main characteristic is that the histological findings are between those of adenocarcinoma and typical carcinoid tumor of the appendix. Goblet cell carcinoid tumors appear almost exclusively in the appendix, and prognosis depends mainly on the stage and the subtype of the histological classification. We report three cases of goblet cell carcinoid tumor in the appendix with different clinical presentation and evolution: a 60-year-old male admitted to the emergency room with acute abdominal pain, diagnosed with acute appendicitis and treated with laparoscopic appendectomy; a 65-year-old male undergoing right hemicolectomy to remove a cecal adenoma, with a goblet cell carcinoid tumor found incidentally in the surgical specimen; and a 77-year-old male with acute appendicitis. We discuss the main pathological and clinical findings, and propose a set of guidelines for clinical practice.
\end{abstract}

\section{Subject Areas}

Gastroenterology \& Hepatology, Oncology, Pathology, Surgery \& Surgical Specialties

\section{Keywords}

Goblet Cell Carcinoid of the Appendix

\section{Purpose}

To clarify and highlight the clinical and pathological characteristics of a rare disease which is often confused with similar tumors with different prognoses; to 
determine the main findings that allow us to classify these tumors for correct treatment.

\section{Introduction}

Goblet cell carcinoid (GCC) tumors occur almost exclusively in the appendix. The variety of their clinical presentations and histological characteristics has aroused debate among pathologists, surgeons, and oncologists. The nomenclature has only recently been standardized: several names have been used to date, including adeno carcinoid, mucinous carcinoid, crypt cell carcinoma and mucin-producing neuro-endocrine tumors [1]. All these terms describe the tumor's pathological characteristics, but none have been found to be completely satisfactory. The main problem with the nomenclature is that the histological findings are inconsistent both qualitatively and quantitatively. GCC is thought to arise from pluripotent intestinal epithelial crypt-base stem cells by dual neuroendocrine and mucinous differentiation [2].

Morphologically, GCCs are composed of goblet cell clusters and carcinoma cells with each component representing at least $30 \%$ of the tumor, and present substantial cytologic atypia [3]. GCCs represent approximately $1 \%$ of all gastrointestinal neoplasms [4].

Tang et al. proposed a subclassification based on histological findings, and designed a new therapeutic algorithm [5]. In 2010, the World Health Organization recognized two different entities: classic goblet cells and mixed adenoneuroendocrine carcinomas, both considered to be neuroendocrine tumors [6].

GCC tumors are small nests of signet ring-like cells with nuclear compression and atypia that affect the base of the crypts with positive neuroendocrine and epithelial markers. No neoplastic changes in the mucosa are usually present.

\section{Case Presentation}

Case 1:

Fifty-year-old male presented at the emergency room with abdominal pain. He had no significant medical history. The pain had started 24 hours previously with vomiting and temperature of $37.5^{\circ} \mathrm{C}$. Physical examination showed tenderness of the low right abdominal quadrant. Plain abdominal $\mathrm{x}$-ray showed no relevant images and emergency lab values were as follows: leukocytes 14.750 (WBC $87.6 \%-12.92 \times 1000 / \mu \mathrm{l}$ ); PCR $68.1 \mathrm{mg} / \mathrm{l}$. The rest of values, including urine examination, were normal.

An abdominal US revealed a tubular-shaped image interpreted as acute appendicitis. During lap appendectomy, a typical phlegmonous appendicitis was found and there were no complications. The postoperative course was uneventful.

At the macroscopic level, pathology analysis of the specimen showed a destructured cecal appendix, with a frosted surface and white deposits. The width of the appendix was $0.3 \mathrm{~cm}$ at serial cuts. These were included in the blocks for microscopic analysis. 
The cecal appendix showed a proliferation of mucin-producing cells, some of which formed nests and others were growing as individual cells with signet ring cell morphology. These cells invaded the entire wall, reaching the periappendiceal tissue. Vascular and perineural permeation were observed. Isolated groups of cells were present in contact with the proximal surgical margin (identified with staples). Immunohistochemistry was performed with the following results: positivity: CKAE1/AE2, CDX2, chromogranin A (focal), synaptophysin (focal) and Ki-67 (50\%).

Diagnosis

Cecal appendix:

-Adenocarcinoma ex-goblet cell carcinoid (group B in Tang's classification), not affecting the epithelium but infiltrating the muscle layer, reaching the periappendiceal adipose tissue.

-Perineural and vascular permeation.

-Acute gangrenous appendicitis with perforation of the wall (UICC pT4a, $7^{\text {th }}$ edition)

-Tumor in contact with surgical proximal margin.

Positivity: CKAE1/AE2, CDX2, chromogranin A, synaptophysin and Ki-67 (50\%).

The patient was discharged but was recalled for surgery after the pathology analysis. A laparoscopic right hemicolectomy was performed, with no pathological findings in the specimen.

\section{Case 2:}

A 65-year-old male with no personal history of interest was diagnosed with a large villous polyp in the cecum that could not be removed by colonoscopy. A laparoscopic right hemicolectomy was performed. Surgery was uneventful, but the patient presented an anastomotic leak eight days later and required re- intervention. An ileostomy was performed, which was closed three months afterwards.

Pathology specimen

Polypoid tumor $6 \mathrm{~cm}$ in diameter, $3 \mathrm{~cm}$ from the ileocecal valve. The rest of the non-tumor mucosa showed no abnormalities. The tumor did not appear to invade the intestinal wall. The appendix was $6 \mathrm{~cm}$ long and its wall $1 \mathrm{~cm}$ thick.

Diagnosis:

Right hemicolectomy for villous adenoma with severe dysplasia. No lymphovascular invasion. Free surgical margin.

- Goblet cell adenocarcinoma of the appendix, infiltrating the entire wall.

- Tumor size $1 \mathrm{~cm}$.

- Lymph nodes: 0/14.

pTNM: pT4pN0.

\section{Case 3}

A 77-year-old male admitted for dyspnea. With the suspected diagnosis of acute appendicitis after abdominal ultrasound, he underwent an appendectomy. Postoperative course was uneventful. The pathology specimen showed adeno- 
carcinoma externally, increased wall thickness and dull serous fibrin. Histological examination showed signs of acute inflammation. Other areas showed a wellpreserved mucosa. At the level of the lamina propria, the periappendiceal muscle and fat presented a concentric proliferation of cells grouped in nests with cytoplasm filled with mucoid tissue displacing the nucleus to the periphery without marked atypia. Sometimes single cells with the same features and lakes of mucin with atypical glandular structures were visible. IHC techniques were positive for CK20, CDX2, chromogranin, synaptophysin, CD56 and Ki-67 (70\%). Goblet cell adenocarcinoma was diagnosed and the patient underwent a right hemicolectomy. No residual tumor or lymph node metastases were observed.

\section{Discussion}

GCC tumors are rare appendiceal tumours, which must be differentiated from appendiceal endocrine tumours.

The appendix is a unique organ whose origin and function are not absolutely clear. This is probably why different types of tumors arise from its cells.

GCC tumors are almost exclusive neoplasms of the appendix. It is thought to be caused in epithelial stem cells of the base of the crypts suffering double neuroendocrine and mucinous differentiation.

Goblet cell tumours are characterized by a predominant submucosal growth, widespread infiltration of the periappendiceal fat in all cases and extensive perineural invasion. They usually lack the formation of a well defined tumour mass. The mucosa is characteristically spared.

WHO recognizes the goblet cell carcinomas as a separate entity in the classification of epithelial tumors of the appendix. They account for only $5 \%$ of appendiceal neoplasms. There is no consensus on whether they are a variant of neuroendocrine tumor or a subtype of adenocarcinoma with neuroendocrine differentiation. Although both pathological and molecular studies are inconclusive, these tumors have the potential to transform in poorly differentiated signet ring of cells adenocarcinomas, with frequent peritoneal dissemination. In this case, it is classified as a subtype of carcinoma adeno-neuroendocrine mixed by WHO (adenocarcinoma exgoblet cell carcinoid).

When these tumors were first described, they were classified as mixed appendiceal adenoneuroendocrine carcinomas with typical characteristics, such as goblet cell clusters [7]. The differences in prognosis made it difficult to classify them as the same pathology, and a distinction was made between typical carcinoid of the appendix and colonic adenocarcinomas. The wide range in the percentage of goblet cell clusters, mucin, nuclear atypia, mitotic count and metastatic ability made it necessary to find a new classification.

In 2008 Tang et al. studied 63 cases recorded at the Memorial Sloan Kettering Cancer Center between 1993 and 2005 and created three different groups based on morphological criteria: typical GCC (Group A), and two types of adenocarcinoma ex-GCC on the basis of the histological features at the primary site of the 
tumor: signet ring cell type (Group B) and poorly differentiated adenocarcinoma type (Group C). The classification is based only on morphological features at the primary site, that is, the appendix. Group A has well-defined goblet cells arranged in clusters or cohesive linear pattern, minimal cytologic atypia, minimal to no desmoplasia, minimal architectural distortion of the appendiceal wall, and degenerative change with extracellular mucin is acceptable. Group B has goblet cells or signet ring cells arranged in irregular large clusters, but lack of confluent sheets of cells, discohesive single file or single cell infiltrating pattern, significant cytologic atypia, desmoplasia and associated destruction of the appendiceal wall. Group $\mathrm{C}$ has at least focal evidence of goblet cell morphology, a component $(>1$ low power field or $1 \mathrm{~mm}^{2}$ ) not otherwise distinguishable from poorly differentiated adenocarcinoma, which may appear as either: a) gland forming; b) confluent sheets or signet ring cells; or c) undifferentiated carcinoma. Extracellular mucin can be present in all groups but is more frequent in groups A and B. They also have different immunohistochemistry characteristics: all groups may be positive for neuroendocrine markers (chromogranin and synaptophysin) but while groups $\mathrm{A}$ and $\mathrm{B}$ showed normal expression of intestinal mucin glycoproteins (MUC1-/MUC2+) and Ki67 < 20\%, group C had abnormal p53 expression, MUC1+/MUC2- pattern, and Ki67 > 70\%. Electron microscopy shows mucin droplets along with electron-dense neurosecretory granules [8]. They contain chromogranin reaction products, and originating from ovoid or discoid EC2 type and D type, and are difficult to find. Table 1 highlights the clinical and pathological differences between GCC, typical carcinoid tumor and adenocarcinoma of the appendix.

Adenocarcinoids, goblet cell tumours, or mucinous adenocarcinoids are all synonymous terms of GCC.

All these tumors arise from a crypt base stem cell that will develop both neuroendocrine and glandular differentiation. The prognosis depends on the stage and subtype of tumor. Median age of presentation is between the fifth and the sixth decade and the most typical presentation is as acute appendicitis. At the time of surgery, very often it is impossible to distinguish between classical inflammatory appendix and a malignant lesion.

There are two other frequent situations: One is a chance finding in the context of a right hemicolectomy for cancer or polyps, as in our second case, and the other is advanced disease with a carcinomatosis which may be detected in the course of an emergency intervention for either intestinal occlusion or inflammatory disease.

The prognosis is intermediate between neuroendocrine tumors and adenocarcinomas, the most important factor is the disease stage. The relationship between the histological findings and prognosis is also in discussion. Some authors think that they have a more aggressive tumor with higher mitotic and proliferative index (Ki-67), and extending the serosa, among other factors.

Hemicolectomy is considered the standard surgical treatment of GCC with additional bilateral salpingo-oophorectomy in female patients. Selection of a 
Table 1. Comparison of clinic-pathological features of goblet cell carcinoid, carcinoid and adenocarcinoma.

\begin{tabular}{|c|c|c|c|}
\hline Tang classification & Goblet cell carcinoid & Carcinoid & Adenocarcinoma \\
\hline \multicolumn{4}{|l|}{ Clinical features } \\
\hline Age & 5 th -6 th decade & 4th decade & 7th decade \\
\hline Carcinoid syndrome & No & Yes & No \\
\hline Primary symptoms & Acute appendicitis & $\begin{array}{c}\text { Acute } \\
\text { appendicitis }\end{array}$ & Mass \\
\hline Gross appearance & $>2 \mathrm{~cm}$, ill defined thickening & $<2 \mathrm{~cm}$ & $>2 \mathrm{~cm}$, well defined mass \\
\hline \multicolumn{4}{|l|}{ Microscopic appearance } \\
\hline Morphology & $\begin{array}{l}\text { Clusters of goblet or signet-ring cells } \\
\text { separated by fibrosis/pools of mucin }\end{array}$ & $\begin{array}{l}\text { Nests of small } \\
\text { cells }\end{array}$ & $\begin{array}{l}\text { Well-formed glands to sheets of poorly } \\
\text { differentiated signet-ring cells }\end{array}$ \\
\hline Atypia & Minimal & Minimal & Marked \\
\hline Mitosis & Rare & Rare & Increased \\
\hline Vascular and perineural invasion & Present & Absent & Present \\
\hline Infiltrative margins & Present & Absent & Present \\
\hline \multicolumn{4}{|l|}{ Special stains } \\
\hline Argyrophil & Positive & Positive & Usually negative \\
\hline Argentaffin & Negative & Positive & Negative \\
\hline Mucicarmine/PAS/PASD & Positive in goblet cells & Negative & Positive \\
\hline \multicolumn{4}{|l|}{ IHC } \\
\hline CEA & + & - & + \\
\hline $\mathrm{CDX} 2$ & + & - & + \\
\hline CAM5.2 & + & - & + \\
\hline CK20 & $+1-$ & - & + \\
\hline CK7 & $+1-$ & - & - \\
\hline CK19 & + & - & - \\
\hline Neuroendocrine markers & $+1-$ & $+/-$ & - \\
\hline Math1 and HD5 & + & - & + \\
\hline $\mathrm{p} 53, \mathrm{p} 16$ & - & - & + \\
\hline \multicolumn{4}{|l|}{ Molecular pathology } \\
\hline $\begin{array}{c}\text { DPC4, Kras, } \beta \text {-catenin mutation and } \\
\text { p53 over expression }\end{array}$ & - & - & + \\
\hline
\end{tabular}

more conservative surgery, such as appendectomy, should be carefully individualized in cases without any risk factor for locoregional spread or metastases or in fragile patients. Treatment of liver metastases might follow standard procedures for neuroendocrine tumours.

Investigations after the initial diagnostic surgical intervention will involve a similar work-up as for high risk $(1-2 \mathrm{~cm})$ appendiceal endocrine tumours. Because GCC bear a higher risk of distant metastases, a chest CT scan is added to the work-up strategy, in addition to a CT scan of abdomen and pelvis or alternatively MRI of the abdomen and pelvis together with somatostatin receptor scin- 
Table 2. Sociodemographic and clinical characteristics.

\begin{tabular}{ccccc}
\hline & Age & Gender & ASA & pTNM \\
\hline Case 1 & 55 & M & 2 & PT4N0M0 \\
Case 2 & 65 & M & 2 & PT4N0M0 \\
Case 3 & 77 & F & 3 & PT3N0M0 \\
\hline
\end{tabular}

tigraphy (SPECT or PET). Lifelong screening for synchronous or metachronous malignancies is recommended. In contrast to appendiceal endocrine tumours CgA determination is not recommended. CEA, CA-19-9 and CA-125 are suggested as tumour markers.

In cases with obvious spread of the disease, 5-Fu based chemotherapy regimens commonly used for colorectal cancer are advised. In cases with obvious spread of the disease, 5-Fu based chemotherapy regimens commonly used for colorectal cancer are advised [9]. Adjuvant therapy with 5-FU and leucoverin is not effective [10]. A case record of a very prolonged complete remission in a patient with disseminated disease has been reported with the Folfox IV regimen [11]. There is no experience with somatostatin analogues, interferon or PRRT because the biology and the pathomolecular features of GCC do not support their use. PRRT could be an option in somatostatin receptor-positive metastatic patients, but is still investigational.

The three cases are different clinical situations. Two of them presented as acute appendicitis and both were completed with right hemicolectomy as it is recommended in most clinical guides [12]. In theory, if the location of the tumor is not in the base of the appendix it could be enough with the appendectomy, but in reality the lack of a correct staging and the possibility or local recurrence make safer to practice a right hemicolectomy. Last case was different. In the context of right hemicolectomy for unresectable polyp, the examination of the appendix showed a GCC.

Differential diagnosis must be performed with typical carcinoid of the appendix and adenocarcinoma (Table 2).

Finally, we have two recommendations for clinical practice:

- The cecal appendix should be routinely analyzed in right hemicolectomy specimens in search of an occult appendiceal carcinoma.

- These tumors should be borne in mind when operating an acute appendicitis, because different surgical techniques are required.

\section{References}

[1] Roy, P. and Chetty, R. (2010) Goblet Cell Carcinoid Tumors of the Appendix: An Overview. World Journal of Gastrointestinal Oncology, 2, 251-258. https://doi.org/10.4251/wjgo.v2.i6.251

[2] Isaacson, P. (1981) Crypt Cell Carcinoma of the Appendix (So-Called Adenocarcinoid Tumor). The American Journal of Surgical Pathology, 5, 213-224. https://doi.org/10.1097/00000478-198104000-00001

[3] Bosman, F., Carneiro, F., Hruban, R. and Theise, N.D. (2010) WHO Classification 
of Tumors of the Digestive System. International Agency for Research on Cancer, Lyon.

[4] McCusker, M.E., Cote, T.R., Clegg, L.X. and Sobin, L.H. (2002) Primary Malignant Neoplasms of the Appendix: A Population-Based Study from the Surveillance, Epidemiology and End-Results Program, 1973-1998. Cancer, 94, 3307-3312. https://doi.org/10.1002/cncr.10589

[5] Tang, L.H., Shia, J., Soslow, R.A., Dhall, D., Wong, W.D., O’Reilly, E., et al. (2008) Pathologic Classification and Clinical Behavior of the Spectrum of Goblet Cell Carcinoid Tumors of the Appendix. The American Journal of Surgical Pathology, 32, 1429-1443. https://doi.org/10.1097/PAS.0b013e31817f1816

[6] Romeo, M., Quer, A., Tarrats, A., Molina, C., Radua, J. and Manzano, J.L. (2015) Appendiceal Mixed Adenoneuroendocrine Carcinomas, a Rare Entity That Can Present as a Krukenbergtumor: Case Report and Review of the Literature. World Journal of Surgical Oncology, 13, 325. https://doi.org/10.1186/s12957-015-0740-1

[7] Edmonds, P., Merino, M.J., LiVolsi, V.A. and Duray, P.H. (1984) Adenocarcinoid (Mucinous Carcinoid) of the Appendix. Gastroenterology, 86, 302-309.

[8] Kanthan, R., Saxena, A. and Kanthan, S.C. (2001) Goblet Cell Carcinoids of the Appendix: Immunophenotype and Ultrastructural Study. Archives of Pathology \& Laboratory Medicine, 125, 386-390.

[9] Pahlavan, P.S. and Kanthan, R. (2005) Goblet Cell Carcinoid of the Appendix. World Journal of Surgical Oncology, 3, 36. https://doi.org/10.1186/1477-7819-3-36

[10] Pham, T.H., Wolff, B., Abraham, S.C. and Drelichman, E. (2006) Surgical and Chemotherapy Treatment Outcomes of Goblet Cell Carcinoid: A Tertiary Cancer Center Experience. The Annals of Surgical Oncology, 13, 370-376. https://doi.org/10.1245/ASO.2006.02.016

[11] Garin, L., Corbinais, S., Boucher, E., Blanchot, J., Le Guilcher, P. and Raoul, J.L. (2002) Adenocarcinoid of the Appendix Vermiformis: Complete and Persistent Remission after Chemotherapy (Folfox) of Metastatic Case. Digestive Diseases and Sciences, 47, 2760-2762. https://doi.org/10.1023/A:1021065407822

[12] Thirlby, R.C., Kasper, C.S. and Jones, R.C. (1984) Metastatic Carcinoid Tumor of the Appendix. Report of a Case and Review of the Literature. Diseases of the Colon \& Rectum, 27, 42-46. https://doi.org/10.1007/BF02554075 


\section{Abbreviations}

GCC: Goblet Cell Carcinoid

WBC: White Blood Cell Count

CK: Citokeratin

WHO: World Health Organization

MRI: Magnetic Resonate

SPECT: Single Photon emission computed tomography

PET: Position emission tomography

CEA: Carcino embriogenic antigen

CA 19.9: Carbohidrate antigen

CA 125: Cancer antigen

5- FU: 5- Fluorouracil

PRRT: Peptid receptor radionuclide therapy

IHC: Inmunohistochemistry

MUC: Mucine cellular

Submit or recommend next manuscript to OALib Journal and we will provide best service for you:

- Publication frequency: Monthly

- 9 subject areas of science, technology and medicine

- Fair and rigorous peer-review system

- Fast publication process

- Article promotion in various social networking sites (LinkedIn, Facebook, Twitter, etc.)

- Maximum dissemination of your research work

Submit Your Paper Online: Click Here to Submit

Or Contact service@oalib.com 